\title{
Utilization and associated factors of emergency contraception among women seeking abortion services in health institutions of Dessie town, North East Ethiopia, 2018
}

\author{
Asres Eshetie Feleke ${ }^{1}$, Tewdros Seyoum Nigussie ${ }^{2}$ and Tibeb Zena Debele $2^{2^{*}}$ (1)
}

\begin{abstract}
Objective: The aim of the study was to assess utilization and associated factors of emergency contraception among women seeking abortion services in Health Institutions of Dessie town, North East Ethiopia, 2018.

Results: Among the interviewed 784 women 400 (51\%) utilized emergency contraception. Women's age of 20-24 years [AOR: 2.10, (95\% Cl 1.200,3.671)], urban residence [AOR: 2.02 (95\% Cl 1.273, 3.218], being single [AOR: 1.71, (95\% Cl 1.176, 2.485)], being knowledgeable on emergency contraception [AOR: 5.66, (95\% Cl 3.976,8.070)], and having favorable attitude towards emergency contraception [AOR: $2.75(95 \% \mathrm{Cl} 1.946,3.881)$ ] were significantly associated factors with the utilization of emergency contraceptives. Emphasis has to give on health education on emergency contraceptives focusing on those women who are from the rural area, older and married women.
\end{abstract}

Keywords: Emergency contraception, Seeking abortion, North East Ethiopia

\section{Introduction}

Emergency contraception refers to birth control modalities that will be used after unprotected sexual intercourse within defined time limits to prevent unwanted pregnancies [1]. Emergency contraceptive is indicated after unprotected sexual intercourse, following sexual abuse, misuse or non-use of contraception [2].

Worldwide, approximately 40 percent of the pregnancies (85 million) were unintended [3]. Women with unintended pregnancy may face the dilemma between terminating the pregnancy or allowing unwanted birth [4].

Every year, In developing countries, at least 22,000 women dies from abortion-related complications [8]. An estimated 620,300 induced abortions were performed in Ethiopia in 2014 [5]. Even if performed safely, abortion

\footnotetext{
*Correspondence: zenatibeb@gmail.com

2 Department of Midwifery, College of Medicine and Health Science, University of Gondar, P.O. Box 196, Gondar, Ethiopia

Full list of author information is available at the end of the article
}

might be painful and may have psychological and physical stress for the women [6, 7].

There are two main emergency contraceptives (EC) modalities; these are the Oral emergency contraceptives and intrauterine devices. The oral EC have various degrees of protection against pregnancy according to the time that they were taken. If it is taken within $72 \mathrm{~h}$ of unprotected sexual intercourse, they reduce the risks of pregnancy by $95 \%[8,9]$. Post-coital insertion $\mathrm{Cu}-\mathrm{IUD}$ within 5-7 days after unprotected sexual intercourse in addition to being an effective method of emergency contraception it can also serve as a safe and effective method of long-term contraception [10].

If emergency contraception are easily available and distributed along with appropriate advocacy activities, millions of unwanted pregnancies and abortions can be averted [11]. Furthermore, the use of EC reduces the cost of expenditures on medical care by preventing unintended pregnancies [8].

In Ethiopia, even though EC pills are distributed free of charge through the support of the non-governmental 
organization and there are many over the counter preparations for sell, still there is a law utilization of emergency contraceptive pills. Therefore, the aim of this study was to assess utilization and associated factors of emergency contraception among women seeking abortion care services in the health institutions of Dessie town.

\section{Main text \\ Methods \\ Study design, period and setting}

An institutional-based cross-sectional study was conducted from August 2, 2018, to January 30, 2019 in Dessie town health institutions. Dessie town is located at $401 \mathrm{~km}$ from the capital city of Ethiopia, Addis Ababa. The town has five Hospitals (one public referral, one public general and three private), eight health centers and twenty-seven private clinics. Currently, there are 10 health institution fully providing safe abortion care services for the community. In those health institutions, 6 months prior to the data collection period, there were 2830 safe abortion cases.

\section{Sample size and sampling procedure}

To estimate a sample size of 784 participants were calculated with single population proportion formula with the following assumptions. The magnitude of EC utilization 9.7\% from a previous study done in Diredawa [12], 95\% confidence interval, $3 \%$ margin of error, a design effect of 2 and non response rate of $10 \%$. Initially, 10 health facilities that provide abortion service were stratified into 5 governmental and 5 private institutions. Then after, out of the 5 institutions, 3 were selected from each group by simple random sampling technique. After proportionally allocating the total numbers of the participants, a systematic random sampling method was employed to select the actual study participants.

\section{Operational definitions}

Utilization of EC: if a woman has any history of EC usage $[13,14]$.

Knowledgeable: Respondents who scored above the mean value of the knowledge assessment questions [15].

Favorable attitude: Respondents who scored above the mean value of attitude assessment questions $[15,16]$.

\section{Data collection instrument and process}

Data was collected by face to face interview using a semistructured and pre-tested questionnaire which is prepared first in English and translated to Amharic and then translated back to English to assure consistency. Ten BSc midwifery holders were involved in the data collection while two MSc holders supervised the data collection process.

\section{Data analysis}

Data were entered with epi-info version7 and analyzed using SPSS version 20 software. Bivariate and multivariable logistic regression analyses were conducted to identify predictors for emergency contraceptive utilization. Variables found to be significant on Bivariate analysis $(\mathrm{p}<0.2)$ were included in the multivariable model. Adjusted odds ratios and 95\% confidence intervals were generated. $\mathrm{p}$-value $<0.05$ were considered statistically significant.

\section{Results}

\section{Socio-demographic characteristics}

A total of 784 women were involved in the study making a response rate of $100 \%$. The mean age of the respondents was 24.28 years with SD of \pm 4.74 . The majority of $621(79.2 \%)$ were urban residents, and 420 (53.6\%) were single (Table 1).

\section{Sexual and reproductive characteristics of respondents}

Four hundred three (51.4\%) of respondents had started first sexual intercourse less than the age of 18 . Among the respondents, $342(43.6 \%)$ have one or more children. Six hundred four (77\%) were first time arrival for termination of pregnancy, 179 (22.8) had a prior history of induced abortion, among those who had a history of induced abortion, 135 (75.4\%) had one episode, and 28 (15.6\%) had more than three induced abortions.

\section{Distance from home to the nearby health institution (in terms of time elapse)}

The respondent's distance from home to the nearby health institution ranges from $1 \mathrm{~min}$ to $720 \mathrm{~min}$. Majority of the respondents $638(81.4 \%)$ stated that stated they could reach in the nearby health institution within $30 \mathrm{~min}$.

\section{Utilization of regular family planning methods}

Five hundred forty-one (69\%) had ever used regular contraceptive methods. Among those who had ever used regular contraceptive method 397 (73.4\%) used an injectables contraceptive.

\section{Knowledge and attitude about emergency contraceptive}

The overall summary index for knowledge and attitude of the respondents about EC disclosed that 434 (55.4\%) were knowledgeable and $376(48 \%)$ had a favorable attitude towards EC.

\section{Utilization of emergency contraception}

In this study 400 (51\%) of respondents had ever used EC; were all of them used EC pills. The main source of information for those who ever used EC were friends 
Table 1 Socio demographic characteristics of women seeking abortion services in health institutions of Dessie town, $2018(\mathrm{n}=784)$

\begin{tabular}{|c|c|c|}
\hline Variables & Frequency & Percent \\
\hline \multicolumn{3}{|l|}{ Age (years) } \\
\hline $13-19$ & 130 & 16.6 \\
\hline $20-24$ & 285 & 36.4 \\
\hline $25-29$ & 259 & 33 \\
\hline$\geq 30$ & 110 & 14 \\
\hline \multicolumn{3}{|l|}{ Residence } \\
\hline Urban & 621 & 79.2 \\
\hline Rural & 163 & 20.8 \\
\hline \multicolumn{3}{|l|}{ Marital status } \\
\hline Single & 501 & 63.9 \\
\hline Married & 283 & 36.1 \\
\hline \multicolumn{3}{|l|}{ Religion } \\
\hline Muslim & 420 & 53.6 \\
\hline Orthodox & 344 & 43.9 \\
\hline Others & 20 & 2.5 \\
\hline \multicolumn{3}{|l|}{ Ethnicity } \\
\hline Amhara & 719 & 91.7 \\
\hline Oromo & 29 & 3.7 \\
\hline Others & 36 & 4.6 \\
\hline \multicolumn{3}{|l|}{ Educational status } \\
\hline No primary education & 55 & 7 \\
\hline Primary education & 180 & 23 \\
\hline Secondary education & 317 & 40.4 \\
\hline Tertiary education & 232 & 29.6 \\
\hline \multicolumn{3}{|l|}{ Father's educational status } \\
\hline No primary education & 480 & 61.2 \\
\hline Primary education & 105 & 13.4 \\
\hline Secondary education & 110 & 14 \\
\hline Tertiary education & 89 & 11.4 \\
\hline \multicolumn{3}{|l|}{ Mother's educational status } \\
\hline No primary education & 614 & 78.3 \\
\hline Primary education & 83 & 10.6 \\
\hline Secondary education & 54 & 6.9 \\
\hline Tertiary education & 33 & 4.2 \\
\hline \multicolumn{3}{|l|}{ Occupation } \\
\hline Housewife & 134 & 17 \\
\hline Merchant & 110 & 14 \\
\hline Government employed & 141 & 18 \\
\hline Student & 285 & 36.4 \\
\hline Servant & 86 & 11 \\
\hline Commercial sex worker & 28 & 3.6 \\
\hline \multicolumn{3}{|l|}{ Living arrangement } \\
\hline With family & 275 & 35.1 \\
\hline With spouse & 209 & 26.6 \\
\hline With peers in a rented house & 60 & 7.7 \\
\hline Alone & 165 & 21 \\
\hline Others & 75 & 9.6 \\
\hline
\end{tabular}

Table 1 (continued)

\begin{tabular}{|c|c|c|}
\hline Variables & Frequency & Percent \\
\hline \multicolumn{3}{|l|}{ Income } \\
\hline$<500$ ETB & 317 & 40.4 \\
\hline 501-1000 ETB & 162 & 20.7 \\
\hline 1001-1500 ETB & 72 & 9.2 \\
\hline 1501-2000 ETB & 92 & 11.7 \\
\hline Above 2000 ETB & 141 & 18 \\
\hline
\end{tabular}

$243(60.8 \%)$, sexual partner $84(21 \%)$, media 50 (12.5\%), health professionals $6(1.5 \%)$, web pages $7(1.7 \%)$ and 10 (2.5\%) other sources,

Respondents who had never used EC mentioned main factors for non-utilization and they are; lack of information 255 (66.5\%), time inconvenience 14 (3.7\%), lack of willingness $19(4.9 \%)$, drugs unavailability 5 (1.3\%), privacy issue $6(1.5 \%)$.

\section{Factors associated with the utilization of emergency contraception}

On the bivariate analysis factors that significantly associated with EC use were: women's age of 20-24 years, urban residence, being orthodox by religion, being single by marital status, father's educational status more than primary and above, having one children and above, knowledgeable on EC having favorable attitude towards EC From In multivariate binary logistic regression analysis; age of respondents 20-24 years $[\mathrm{AOR}=2.10,95 \%$ CI $1.200-3.671]$, urban residence $[\mathrm{AOR}=2.02,95 \% \mathrm{CI}$ $1.273-3.218]$, being single by marital $[\mathrm{AOR}=1.71,95 \%$ CI 1.176-2.485], knowledgeable on EC [AOR $=5.66,95 \%$ CI 3.976, 8.070], having favorable attitude towards EC $[\mathrm{AOR}=2.75,95 \% \mathrm{CI} 1.946-3.881]$ were found to be significantly associated with EC (Table 2).

\section{Discussion}

This study finds out that 400 (51\%) of women who came for abortion service had ever used EC (95\% CI 47.9, 54.6). This is in agreement with the study that was done among abortion care seekers in China (48.8\%) [17].

This finding is lower than the studies that were done in North India (70\%) in Durban South Africa (62.1\%) and among women of the reproductive age group in India [18-20]. Possible reasons for this difference might be due to the differences in the study area, study population, and knowledge about EC. In the North Indian study, the participants were recently married and data were collected from a single government health institution. Additionally, 
Table 2 Bivariate and multivariate logistic regression analysis of factors associated with EC use among women seeking abortion service in Health Institutions of Dessie town, North East Ethiopia, $2018(n=784)$

\begin{tabular}{|c|c|c|c|c|}
\hline \multirow[t]{2}{*}{ Utilization } & \multicolumn{2}{|l|}{ Utilization } & \multirow[t]{2}{*}{ COR $(95 \% \mathrm{Cl})$} & \multirow[t]{2}{*}{ AOR $(95 \% \mathrm{Cl})$} \\
\hline & Yes $(n=400)$ & No $(n=384)$ & & \\
\hline \multicolumn{5}{|l|}{ Age (years) } \\
\hline $13-19$ & 55 & 75 & $1.28(0.76,2.16)$ & \\
\hline $20-24$ & 171 & 114 & $2.62(1.67,4.14)$ & $2.10(1.200,3.671)$ \\
\hline $25-29$ & 134 & 125 & $1.88(1.19,2.97)$ & \\
\hline$\geq 30$ & 40 & 70 & 1 & \\
\hline \multicolumn{5}{|l|}{ Residence } \\
\hline Rural & 47 & 116 & 1 & \\
\hline Urban & 353 & 268 & $3.25(2.24,4.73)$ & $2.02(1.273,3.218)$ \\
\hline \multicolumn{5}{|l|}{ Marital status } \\
\hline Married & 129 & 154 & 1 & \\
\hline Single & 271 & 230 & $1.40(1.05,1.89)$ & $1.71(1.176,2.485)$ \\
\hline \multicolumn{5}{|l|}{ Number of children } \\
\hline None & 240 & 202 & 1 & \\
\hline One and above & 160 & 182 & $0.74(0.56,0.98)$ & \\
\hline \multicolumn{5}{|l|}{ Religion } \\
\hline Muslim & 193 & 227 & 1 & \\
\hline Orthodox & 193 & 151 & $1.50(1.13,2.00)$ & \\
\hline Other & 14 & 6 & $2.74(1.03,7.23)$ & \\
\hline \multicolumn{5}{|l|}{ Ethnicity } \\
\hline Amhara & 357 & 362 & $0.56(0.28,1.12)$ & \\
\hline Oromo & 20 & 9 & $1.26(0.44,3.55)$ & \\
\hline Other & 23 & 13 & 1 & \\
\hline \multicolumn{5}{|c|}{ Father's educational status } \\
\hline No primary education & 204 & 276 & 1 & \\
\hline Primary education & 64 & 41 & $2.11(1.37,3.25)$ & \\
\hline Secondary education & 71 & 39 & $2.46(1.60,13.79)$ & \\
\hline Tertiary education & 61 & 28 & $2.95(1.82,4.78)$ & \\
\hline \multicolumn{5}{|l|}{ Knowledge } \\
\hline Not knowledgeable & 82 & 268 & 1 & \\
\hline Knowledgeable & 318 & 116 & $8.96(6.47,12.41$ & $5.66(3.976,8.070)^{* *}$ \\
\hline \multicolumn{5}{|l|}{ Attitude } \\
\hline Unfavorable attitude & 140 & 268 & 1 & \\
\hline Favorable attitude & 260 & 116 & $4.29(3.18,5.89)$ & $2.75(1.946,3.881)^{* *}$ \\
\hline
\end{tabular}

** p-value $<0.05$

their knowledge score was also higher than the current study. In the Durban study, the main source of information about EC were health care professional's contrary to the current study where the majority of the respondents obtained information about EC from their friends who might not share correct information that intern leads to low utilization.

This finding is higher than studies that were done among abortion seekers in Jimma specialized hospital were none of them ever used EC, Dire-dawa (9.7\%) and India (1.155\%) had ever used EC [12, 21, 22]. this difference might be due to the difference in socio-demographic, cultural or developmental differences of the study with India. In the Jimma and Diredawa study, the knowledge and attitude of the participants were lower than the current study, which may reduce utilization of EC.

Women's age was a significant factor to EC use. Women in their age 20-24 years were 2.10 times more likely utilized EC as compared with women aged $\geq 30$ years. This is in agreement with the studies conducted among abortion seekers in Dire-dawa [12], and South Africa [23]. Possible 
reasons for this might be women in this age group might not use regular contraceptive methods consistently due to cultural influence which might lead them to use EC. In addition, this group of women is mostly college students that might have the opportunity to get information about EC after unprotected sexual intercourses from their peer which intern increase the utilization.

Residence was an important determining factor for EC use. Those women who were living in an urban area were 2.02 times more likely utilized EC as compared with those who were living in the rural area. This is consistent with the study that was done in Arbaminch [24]. The possible reasons might be women living in urban areas could be more exposed to media, which might create awareness about family planning methods including EC. Another explanation could be the fact that EC is more accessible in the urban areas than their rural counterparts. On the contrary, a shortage of media coverage in the rural area could have a negative influence utilization of EC for women living in the rural area.

Marital status was significantly associated with EC use. Women who were single were 1.71 times more likely to utilized EC as compared with those who were married. This is in agreement with the study that was done in Dire-dawa [22]. The possible explanation could be single women might not use regular contraceptive methods consistently which increases the utilization. In addition, single women could have unplanned sexual intercourse not feasible to use regular contraceptive methods which intern leads to more utilization of EC.

Women who were knowledgeable about EC were 5.66 times more likely to utilize. This is coherent with studies that were done among abortion seekers in Dire-dawa [22], South Africa [24]. This might be explained by knowing effectiveness, where they can get when they can use EC may help to use EC.

Attitude towards EC was significantly associated with the use of EC. Participates who had a favorable attitude towards EC were 2.75 times more likely to utilized EC. This is consistent with studies done in Debre-Markos higher institutions [25]. The above reports might be explained with women who have a favorable attitude towards EC might want to know more about EC and to use it.

\section{Limitations of the study}

Questions that had sensitive nature like age of first sexual intercourse, history of previous induced abortion might create social desirability bias.

\section{Abbreviations}

AOR: adjusted odds ratio; Cl: confidence interval; COR: crude odds ratio; CuIUD: copper bearing intrauterine device; EC: emergency contraceptive.

\section{Acknowledgements}

We are very grateful to the University of Gondar for approval of the ethical clearance. We are also grateful to the Dessie town health institution administrators for their permission by giving us a support letter to undertake the study. The study participants, and data collectors also deserved warm appreciation.

\section{Authors' contributions}

$A E$, TS involved in the conception and design of the study, participated in data collection, analyzed the data and drafted the manuscript and approve the final version of the manuscript. TZ approved the proposal with some revisions, participated in data analysis and interpretation revised subsequent drafts of the manuscript and approves the last version of the manuscript. All authors read and approved the final manuscript.

\section{Funding}

No funding.

\section{Data availability}

The authors declare that the data regarding this manuscript can be accessed as per the request of any interested body and can be submitted for publication in Spring Nature as supplementary materials.

\section{Ethics approval and consent to participate}

Ethical clearance was obtained from the School of Midwifery under the delegation from the Ethical Review Board of the University of Gondar. Written consent was obtained from each study participants after informing the objective of the study. For minors under the age of 18 consent was obtained from patients or guardians. In the consent, statements about the potential risk, benefit, and confidentiality were included. Ethics committee approval was obtained for this written consent.

\section{Consent for publication}

Not applicable.

\section{Competing interests}

The authors declare that they have no competing interests.

\section{Author details}

${ }^{1}$ Department of Midwifery, School of Nursing and Midwifery, Wollo University, P.O. Box 1145, Dessie, Ethiopia. ${ }^{2}$ Department of Midwifery, College of Medicine and Health Science, University of Gondar, P.O. Box 196, Gondar, Ethiopia.

Received: 8 August 2019 Accepted: 3 October 2019

Published online: 22 October 2019

\section{References}

1. Schorge JO, Hoffman BL, Bradshaw KD, Halvorson LM, Schaffer Jl, Corton MM. Williams gynecology. New York: McGraw-Hill Medical; 2008.

2. Organization WH. Fact sheet on the safety of levonorgestrel-alone emergency contraceptive pills (LNG ECPS). Geneva: World Health Organization; 2010.

3. Sedgh GR. Intended and unintended pregnancies worldwide in 2012 and recent trends. BMC. 2016;45(3):301-4.

4. Blas E, Kurup AS. Equity, social determinants and public health programmes. Geneva: World Health Organization; 2010.

5. Moore AM, Gebrehiwot Y, Fetters T, Wado YD, Bankole A, Singh S, et al. The estimated incidence of induced abortion in Ethiopia, 2014: changes in the provision of services since 2008. Int Perspect Sex Reprod Health. 2016;42(3):111.

6. Gabbe SG, Niebyl JR, Simpson JL, Landon MB, Galan HL, Jauniaux ER, et al. Obstetrics: normal and problem pregnancies. Amsterdam: Elsevier Health Sciences; 2016.

7. Pourreza A, Batebi A. Psychological consequences of abortion among the post abortion care seeking women in Tehran. Iran J Psychiatry. 2011;6(1):31.

8. Trussell J, Raymond EG, Cleland K. Emergency contraception: a last chance to prevent unintended pregnancy. Contemp Read Law Soc Justice. 2017;4(2):7-38. 
9. Levy DP, Jager M, Kapp N, Abitbol J-L. Ulipristal acetate for emergency contraception: postmarketing experience after use by more than 1 million women. Contraception. 2014;89(5):431-3.

10. Cleland K, Raymond EG, Westley E, Trussell J. Emergency contraception review: evidence-based recommendations for clinicians. Clin Obstet Gynecol. 2014;57(4):741.

11. Gold E. Emergency contraception in Ethiopia: provider and user attitudes and behaviors (white paper report). Washington DC: DKT International; 2012.

12. Abate M, Assefa N, Alemayehu T. Knowledge, Attitude, Practice, and Determinants Emergency Contraceptive Use among Women Seeking Abortion Services in Dire Dawa, Ethiopia. PLoS ONE. 2014;9(10):e110008.

13. Ahmed FA, Moussa KM, Petterson KO, Asamoah BO. Assessing knowledge, attitude, and practice of emergency contraception: a crosssectional study among Ethiopian undergraduate female students. BMC Public Health. 2012;12(1):110.

14. Temesgen K, Workie A, Tsegaye D. Assessment of knowledge, attitude and practice towards emergency contraceptives and associated factors among Wollo University (Dessie Campus) undergraduate female students in Dessie, Ethiopia. J Epidemiol Public Health R. 2017:2(3):1027.

15. Habitu YA, Yeshita HY, Dadi AF, Galcha D. Prevalence of and factors associated with emergency contraceptive use among female undergraduates in Arba Minch University, Southern Ethiopia: a cross-sectional study. Int J Popul Res. 2015;2018:2018.

16. Shiferaw BZ, Gashaw BT, Tesso FY. Factors associated with utilization of emergency contraception among female students in Mizan-Tepi University, South West Ethiopia. BMC Res Notes. 2015:8(1):817.

17. Meng C-X, Gemzell-Danielsson K, Stephansson O, Kang J-Z, Chen Q-F, Cheng L-N. Emergency contraceptive use among 5677 women seeking abortion in Shanghai, China. Hum Reprod. 2009;24(7):1612-8.

18. Gupta RK, Singh P, Gupta C, Kumari R, Langer B, Gupta R. Emergency contraception: knowledge, attitude and practices among recently married females in a rural area of North India. Int J Res Med Sci. 2017:5(10):4450.
19. Shah JV, Patel JM, Patni KN, Chacko S. Knowledge, practices and perception of emergency contraceptive pills among married women in community. World J Pharm Pharm Sci. 2016;5(7):1021-33. https://doi. org/10.20959/wjpps20167-7134.

20. Naidoo U, Zungu LI, Hoque M. Awareness, utilization and attitudes towards emergency contraception among women attending a primary health care clinic in Durban, South Africa. Biomed Res. 2013;24:341-6.

21. Tesfaye T, Tilahun T, Girma E. Knowledge, attitude and practice of emergency contraceptive among women who seek abortion care at Jimma University specialized hospital, southwest Ethiopia. BMC Women's Health. 2012;12(1):3.

22. Kathpalia SK. Emergency contraception: knowledge and practice among women and the spouses seeking termination of pregnancy. Med J Armed Forces India. 2016:72(2):116-9.

23. Osa-Izeko O, Govender R, Ross A. Self-reported knowledge and use of emergency contraception among women presenting for termination of pregnancy. South Afr Fam Pract. 2016;58(4):158-63.

24. Fekadu Y. Knowledge attitude and utilization of emergency contraception among health science and medical students of Arba Minch University, 2015. J Women's Health Care. 2017:6(383):2167-0420.

25. Abera H, Mokonnen M, Jara D. Knowledge-attitude-utilization-of-emergency-contraceptive-and-associated-factors-among-female-students-ofdebre-markos-higher-institutions-northwest-ethiopia. Fam Med Med Sci Res. 2014;3:4-11.

\section{Publisher's Note}

Springer Nature remains neutral with regard to jurisdictional claims in published maps and institutional affiliations.
Ready to submit your research? Choose BMC and benefit from:

- fast, convenient online submission

- thorough peer review by experienced researchers in your field

- rapid publication on acceptance

- support for research data, including large and complex data types

- gold Open Access which fosters wider collaboration and increased citations

- maximum visibility for your research: over $100 \mathrm{M}$ website views per year

At BMC, research is always in progress.

Learn more biomedcentral.com/submissions 